\title{
What media arts can teach us about technology and its use
}

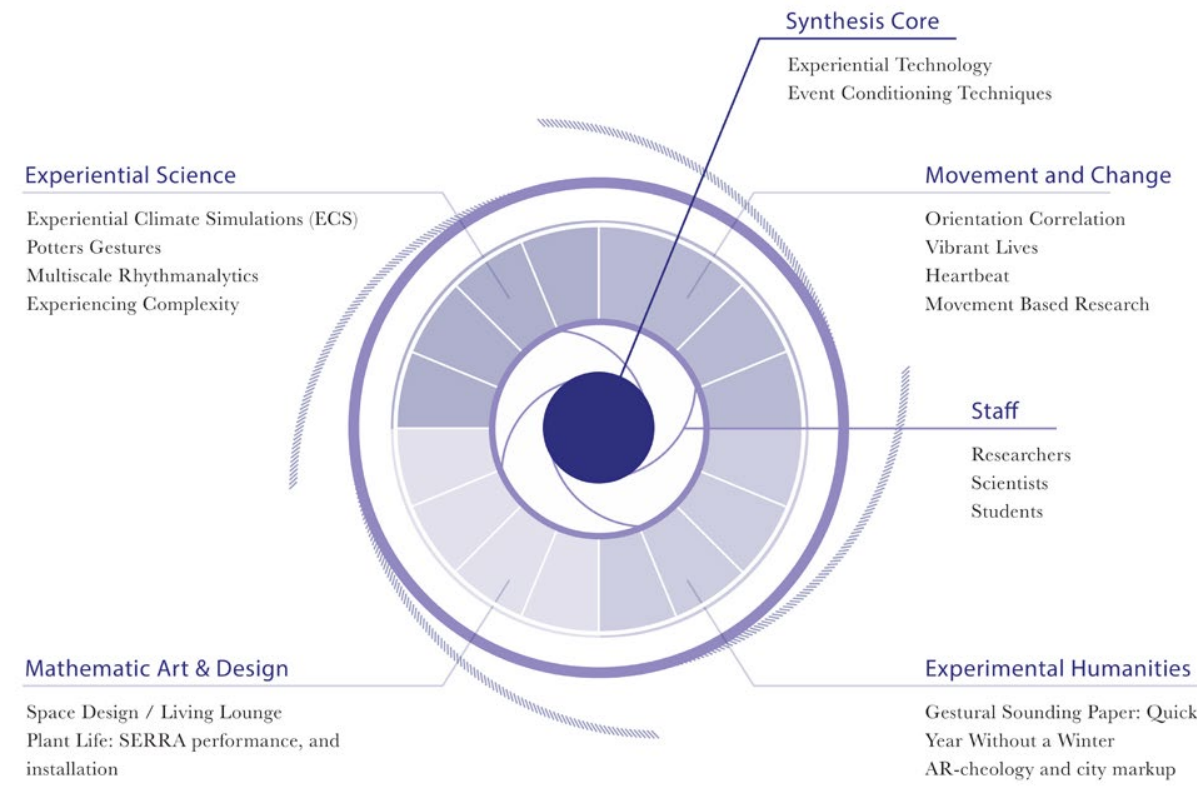

Professor Sha is a theoretical

mathematician who studied at Harvard

\section{cother}

an increasingly familia concept However

Professor Sha believes it is now time to

also think about the 'ecology of things' as

the so-called 'wicked problems' of the 21 s

as climate change, environmental pollution

and global poverty.

The Synthesis Center is where such

thinking can take place in what Professor

Sha calls a 'fresh kind of practice, blending

process philosophy, computer media

and theatre arts, and critical studies of

technology, ecology and economy'. In

this way the center seeks to produce new
knowledge about how people, technology

knowledge about how people, techno
and society articulate creatively and

expressively in the $2^{1 \text { st century. }}$
The Synthesis Center for Transversal Art, Philosophy and Technology reverses the siloing of
knowledge and fuses specialized know-how to tackle questions that cut across academic disciplines.

\section{ORIGINS}

The Synthesis Center for Transversal

Art, Philosophy and Technology

eveloped previously at the Topological

Melip ab at Concordia University in

Montréal, Canada. The lab applied the

mathematical concept

of topology - how

the properties of

geometric objects

are preserved under

as stretching or

twisting, to computational media.

Researchers worked on various projects

and installations, for example a video

art project on the concept of fire which

combined camera-based motion tracking

and gesture-oriented programming

sofware to help viewers interact

with projections on screen. Sudden

on-screen but palpable illusion that they

had caught elemental fire.
A home for adventurous people to invent new ways of thinking and imagining about things.
Researchers from different arts, humanities, science and technology events which crete erith and and cultural value. They go beyond art as creative experience to look at how artistic methods can inform technologica research. For example, lighting, rhythm explored how theatrical grade digital echnology can be used to enliven everyday public spaces. In addition, ( touched, and light sculptures have been created that respond to movement and gesture.

The Synthesis Center is also about transtormation and changing the way people do things. Profssor Sha explains Trely sitting an enginer and an atist and a phing an transforming each discipline's own ways of doing things, with care.' ints in which we wo to live, in which we are not the most

The Synthesis Center is an equally creative, transdisciplinary space for the exploration of a new generation computer-augmented responsive environments. The atelier is modelled on a wo krowops of the Renaissance and dlo draws on contemporary concepts physical action theatre, media labs and design studios.

PEOPLE AS WELL AS SPACE More than a physical space, the Synthesis Center is a group of people who come together and use

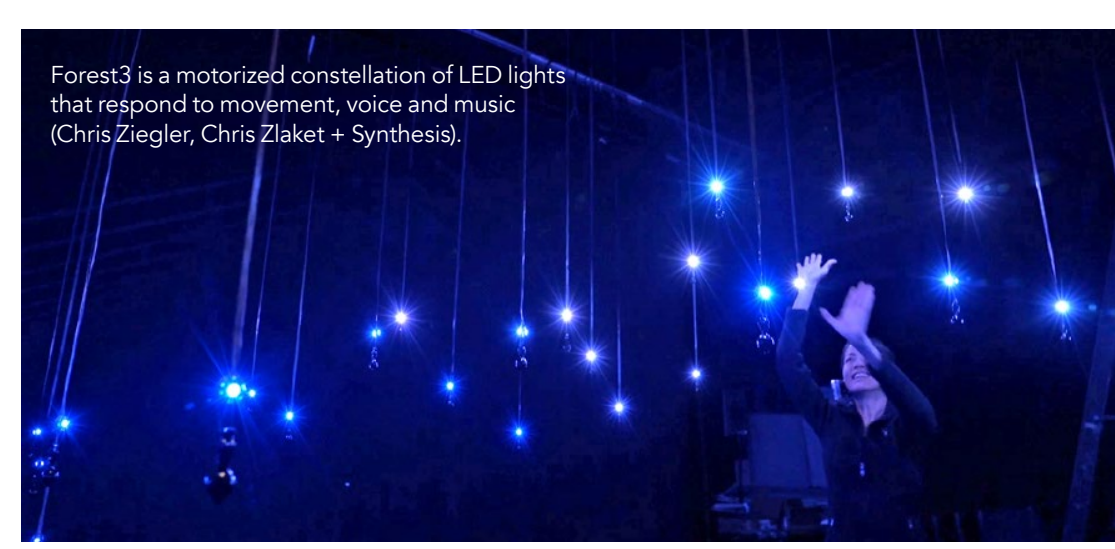
The Synthesis Center's output is based on a series of 'research
clusters' or themes.

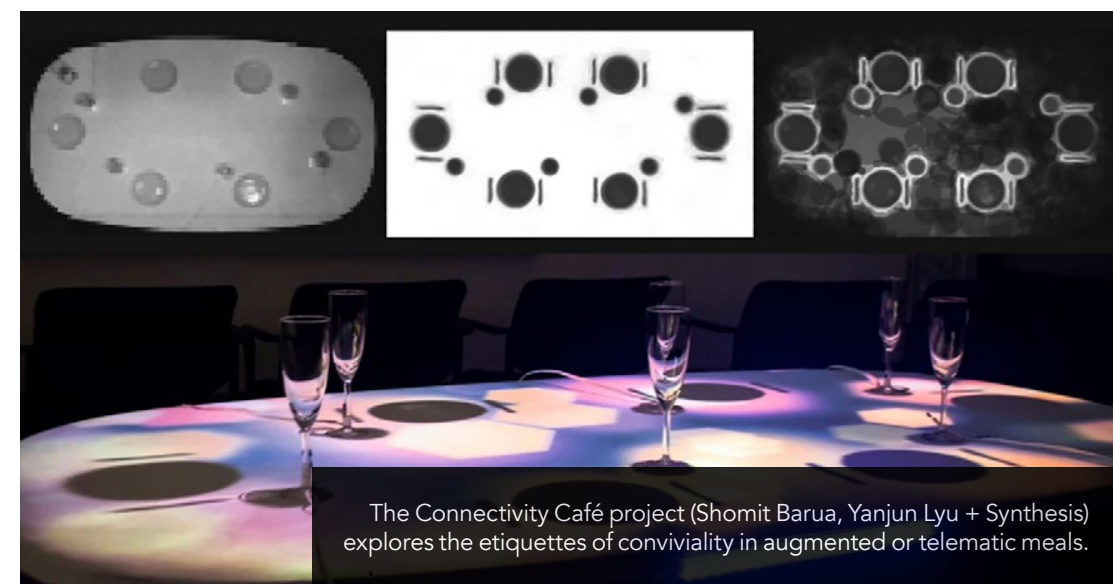


